\title{
Slowered Turnover of Norepinephrine in the Brain Associated with an Acute Elevation in Blood Pressure of Rats*
}

\author{
Akira Iто, M.D., ** Kenjiro TANAKA, M.D., *** \\ and Teruo OMAE, M.D.
}

\section{SUMmary}

Acute responses of blood pressure and turnover of norepinephrine in the brain to intracisternally injected guanethidine were studied in rats. Systolic blood pressure in guanethidine-treated rats showed a dose-relating rise for over $9 \mathrm{hrs}$, while norepinephrine contents in cortex-cerebellum, brain stem and heart were not affected.

The endogenous norepinephrine in brain samples, however, did not decrease against $\alpha$-methyl-p-tyrosine to result in regression coefficients significantly different from those in the saline-treated group whereas nor epinephrine in heart was reduced similarly in the 2 groups, indicating a slowered turnover of norepinephrine selectively in the brain. The results may indicate that the retarded norepinephrine turnover in the brain is causatively related with an acute elevation in blood pressure.

\section{Additional Indexing Words:}

Rat Brain Heart Guanethidine $\alpha$-methyl-p-tyrosine Blood pressure Norepinephrine turnover

$7 \mathrm{HE}$ brain amines including norepinephrine (NE) and serotonin (5HT) are known to concentrate in the specific neuronal systems originated in the brain stem, ${ }^{1 \prime}$ where the central regulatory function of blood pressure has been also demonstrated. ${ }^{2}$ )

Although these biogenic amines have been recently suggested to bear important roles in the central regulation of blood pressure, ${ }^{3)-5)}$ their contribu-

From the Second Department of Internal Medicine, Faculty of Medicine, Kyushu University, Fukuoka, 812 Japan.

* This work was supported by Science Grant from Miyazaki Prefecture, and was preliminarily presented at the 47th Annual Meeting of Japanese Endocrinological Society, Tokyo, 1974: Folia Endocrinol. Jap. 50 (2): 632, 1974.

** Present address: Dcpartment of Medicine, Kyushu University Balneotherapeutic Institute.

*** Present address: Department of Internal Medicine, Miyazaki Medical College, Kumano, Miyazaki, 889-21 Japan.

Address for reprints request: Akira Ito, M.D., Department of Medicine, Kyushu University Balneotherapeutic Institute, 4546 Tsurumihara, Beppu, 874 Japan.

Received for publication December 4, 1974. 
tion in the initiation and maintenance of various types of experimental hypertension remains so far obscure. Yamori et $\mathrm{al}^{(1,8)}$ in rats with spontaneous hypertension and Nakamura et $\mathrm{al}^{8}$ ) in those induced by DOCA-saline loading both reported a reduction in turnover of the brain NE without significant alteration in the content at a stage of sustained hypertension, imputing the reduced turnover could be causatively related with those hypertensive mechanisms.

Indeed, NE turnover dynamically balancing over synthesis, storage, catabolism, release or uptake ${ }^{9,10 /}$ would be related more profoundly with roles of the brain NE as a central neurotransmitter than its relatively static level.

However, interpretation of the reduced turnover of the brain NE in experimental hypertension ${ }^{6-8)}$ is difficult, partly because it remains unknown if slowering of $\mathrm{NE}$ metabolism selectively in the brain could raise the level in blood pressure.

The present experiment was, therefore, undertaken to study the possibility in rats with use of guanethidine which has been reported to concentrate positively into the adrenergic neurones and inhibit release of catecholamines, especially of NE, blocking the response to sympathetic nerve activity and sensitizing effectors to NE, without significant affect on $5 \mathrm{HT}$ metabolism. ${ }^{11-13}$ )

\section{METHODS}

Sprague-Dawley male rats, weighing 150-200 Gm, were used throughout steps in the present study.

Blood pressure response to intracisternal (i.C.) injection of guanethidine

Either $500 \mu \mathrm{g} / \mathrm{Kg}$ or $1 \mathrm{mg} / \mathrm{Kg}$ of guanethidine sulfate (CIBA-Geigy<Japan $>$, Ltd, Tokyo) solved in $25 \mu \mathrm{l}$ of $0.9 \%$ saline just before use was i.C. injected according to the method by Schanberg et al ${ }^{14)}$ in respectively 6 or 5 rats, and response in the systolic blood pressure was compared with that in rats administered i.C. with the vchicle, $25 \mu \mathrm{l}$ of $0.9 \%$ saline.

Systolic blood pressure before and for $8 \mathrm{hrs}$ after the injection was monitored by a tail-plethysmographic cuff method with recording on discoid papers (Ueda Inst Co Ltd, Tokyo: UsM-105) in conscious state.

The experiment was started after confirming the blood pressure became lowered and stabilized during preconditioning of animals for 6 days to the apparatus as described elsewhere. ${ }^{3)}$

Effect of i.C. injection of guanethidine on the level and turnover of $\mathcal{N E}$ in brain and heart

After $3 \mathrm{hrs}$ of i.C. pretreatment with either $1 \mathrm{mg} / \mathrm{Kg}$ of guanethidine sulfate in 20 rats or $25 \mu \mathrm{l}$ of $0.9 \%$ saline in 19 and after $9 \mathrm{hrs}$ of the former in 4 , experimental and control rats in each 5 were decapitated under light ether anesthesia. Brain 


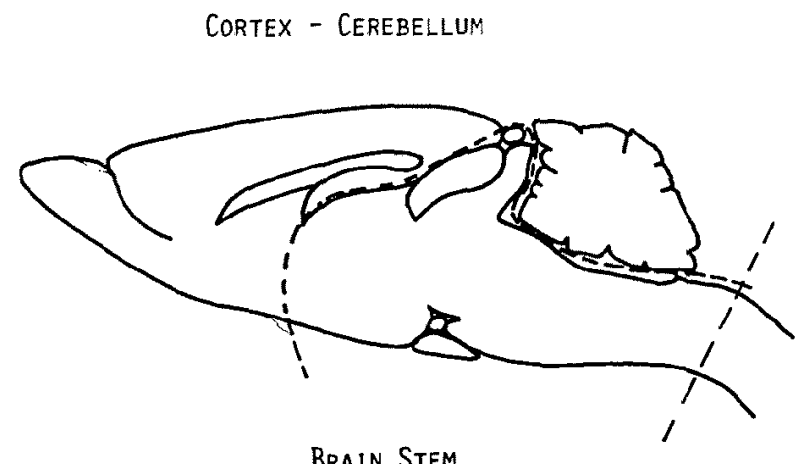

Fig. 1. Side-view of the rat brain being illustrated the sphere of the samples including cortex-cerebellum and brain stem.

and heart were immediately taken out, and the former was divided into cortex-cerebellum and brain stem on an ice-cold glass plate, being kept frozen until the time of assay. As illustrated in Fig. 1, brain stem was separated rostrally along anterior commisure and superior colliculi, laterally at cerebellar peduncles and caudally at dorsal origin of the 1st cervical nerves so that the sample in the present study was expected to consist roughly of thalamus, hypothalamus, midbrain, pons, and medulla oblongata. ${ }^{3,15)}$

NE was eluted and determined by the modified method of Barchas et al $\left.{ }^{16}\right)$ with use of IRC- 50 columns.

Another 29 rats received hereafter intraperitoneal (i.p.) injection every $3 \mathrm{hr}$ with $250 \mathrm{mg} / \mathrm{Kg}$ of DL- $\alpha$-methyl-p-tyrosine (Nakarai Chem, Ltd, Kyoto), a specific depletor of tyrosine hydroxylase, suspended in $1 \mathrm{ml}$ of $0.9 \%$ saline. The animals, each 4 to 5 in either group, were then sacrificed as described above after 3,6, and $9 \mathrm{hrs}$ of the lst injection, and NE in samples were similarly decided. Turnover of the endogenous NE was estimated on the regression co-efficient $(k)^{17)}$ of decline of the levels after block of synthesis by $\alpha$-methyl-p-tyrosine. ${ }^{81,9)}$

Results were expressed as means \pm S.E.M., and Fisher's t-test was performed for all statistical analyses.

\section{RESULTS}

Blood pressure response to i.C. injection of guanethidine (Fig. 2)

Intracisternally applied guanethidine caused a dose-related elevation in blood pressure. Systolic blood pressure in 5 rats injected i.C. with $1 \mathrm{mg} / \mathrm{Kg}$ guanethidine significantly rose after $2 \mathrm{hrs}$ from $113 \pm 4 \mathrm{mmHg}$, reached at the maximum of $142 \pm 5 \mathrm{mmHg}$ after $5 \mathrm{hrs}$ and remained elevated even after $8 \mathrm{hrs}$. Five hundred $\mu \mathrm{g} / \mathrm{Kg}$ of the drug also evoked a similar increase from $116 \pm 2 \mathrm{mmHg}$ to $141 \pm 7 \mathrm{mmHg}$, however, ceasing gradually.

Whereas, the i.C. administration of the vehicle revealed no significant change. 


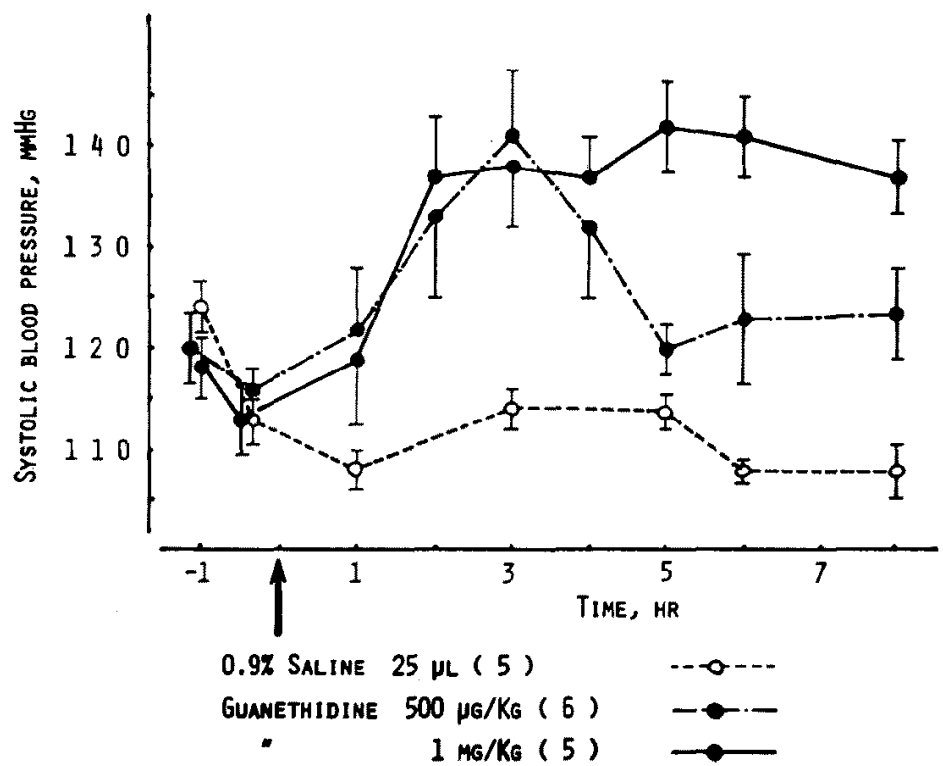

Fig. 2. Blood pressure response to intracisternal (i.C.) injection of guanethidine. Either $500 \mu \mathrm{g} / \mathrm{Kg}$ or $1 \mathrm{mg} / \mathrm{Kg}$ of guanethidine in $25 \mu \mathrm{l}$ of $0.9 \%$ saline was i.C. injected in rats to be compared the systolic blood pressure reaction with that in those treated with the vehicle.

Table I. Wet Weight and Initial Level of Norepinephrine in Brain and Heart

\begin{tabular}{l|r|r|r|r}
\hline & No. & $\begin{array}{r}\text { Guanethidine } \\
\text {-treated }\end{array}$ & No. & Saline-treated \\
\hline Wet weight, mg & & & & \\
$\quad$ Brain stem & 20 & $498.7 \pm 8.6$ & 19 & $503.1 \pm 7.3$ \\
$\quad$ Cortex-Cerebellum & 20 & $1,273.1 \pm 20.4$ & 19 & $1,251.7 \pm 14.4$ \\
$\quad$ Heart & 20 & $706.5 \pm 25.9$ & 20 & $721.1 \pm 24.2$ \\
Level of norepinephrine, ng/Gm & & & & \\
Brain stem & 5 & $386.1 \pm 31.8$ & 4 & $416.6 \pm 70.5$ \\
Cortex-Cerebellum & 5 & $141.7 \pm 14.7$ & 5 & $188.4 \pm 21.4$ \\
Heart & 5 & $649.4 \pm 54.4$ & 5 & $622.2 \pm 56.8$
\end{tabular}

Wet weight and norepinephrine level as meas \pm S.E.M. in the tissue samples after 3 hrs of intracisternal administration with either $1 \mathrm{mg} / \mathrm{Kg}$ of guanethidine or $25, t$ of $0.9 \%$ saline are listed. None of them are significantly different between the 2 groups.

Effect of i.C. injection of guanethidine on level and turnover of $\mathcal{N E}$ in brain and heart (Tables I and II, Fig. 3)

Wet weight and NE level were not affected after 3 hrs of i.C. administration with $1 \mathrm{mg} / \mathrm{Kg}$ of guanethidine (Table I).

The endogenous levels in samples of the saline-treated animals gradually 

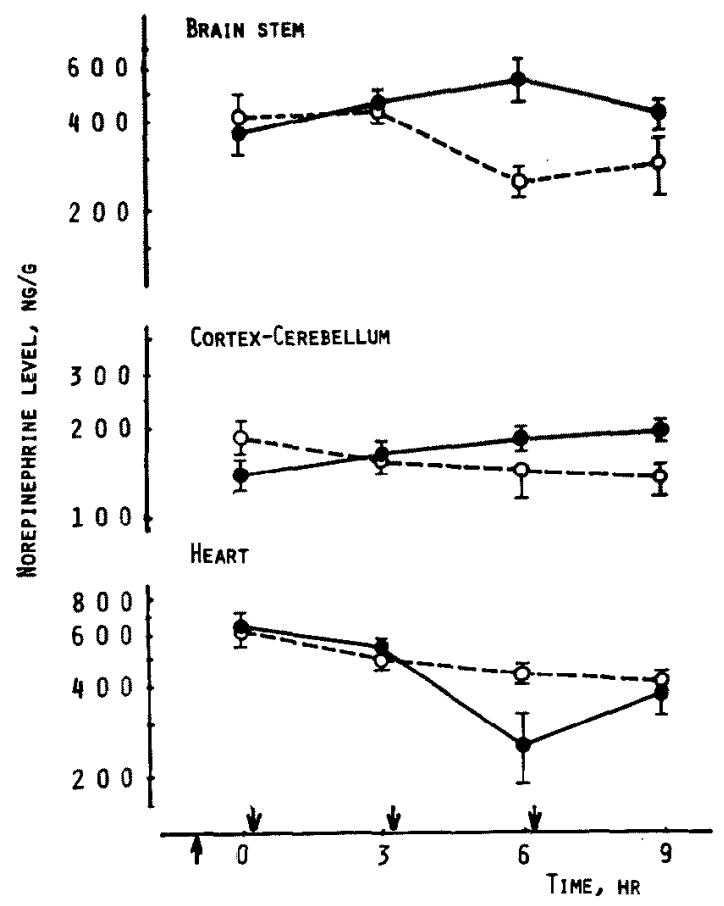

(Guanethidine $1 \mathrm{mg} / \mathrm{Kg}, \mathrm{I}, \mathrm{Cist},(-\mathrm{C}$ -

| a-METHYL-P-TYROSINE 250 mG/KG, I.P.(--0---, -

Fig. 3. Regression of endogenous levels of norepinephrine in tissue samples following a-methyl-p-tyrosine.

After $3 \mathrm{hrs}$ of pretreatment with either $1 \mathrm{mg} / \mathrm{Kg}$ of guanethidine or $25 \mu \mathrm{l}$ of $0.9 \%$ saline $(\uparrow), 250 \mathrm{mg} / \mathrm{Kg}$ of 3 -methyl-p-tyrosine was intraperitoneally injected in every $3 \mathrm{hrs}(\downarrow)$.

Table II. Co-efficient of Norepinephrine Regression in Brain and Heart

\begin{tabular}{l|c|c|c|c}
\hline & \multicolumn{4}{|c}{$\mathrm{k}(\mathrm{mean} \pm$ S.E.M.)/hr } \\
& No. & Guanethidine-treated & No. & Saline-treated \\
\hline Brain stem & 13 & $+0.183 \pm 0.027^{*}$ & 14 & $-0.199 \pm 0.026$ \\
Cortex-Cerebellum & 15 & $+0.115 \pm 0.013^{*}$ & 14 & $-0.160 \pm 0.021$ \\
Heart & 15 & $-0.206 \pm 0.020$ & 15 & $-0.181 \pm 0.021$
\end{tabular}

Co-efficient $(\mathrm{k} / \mathrm{hr})$ of norepinephrine regression during $9 \mathrm{hrs}$ after $250 \mathrm{mg} / \mathrm{Kg}$ of $\alpha$-methyl-ptyrosine intraperitoneally applied in every $3 \mathrm{hrs}$ was calculated on the tissues of rats illustrated in Fig. 3.

* $\mathrm{P}<0.001$, different from the saline-treated group. 
decreased after i.p. injection of $\alpha$-methyl-p-tyrosine during observation for $9 \mathrm{hrs}$, while those in brain stem and cortex-cerebellum in the guanethidineapplied group did not show any decline (Fig. 3).

$\mathrm{NE}$ contents in $\mathrm{ng} / \mathrm{Gm}$ of wet weight of the brain samples in 5 rats listed in Fig. 3 who had received i.C. guanethidine and subsequent i.p. $\alpha$-methylp-tyrosine were $185.4 \pm 14.1$ in cortex-cerebellum and $553.8 \pm 90.5$ in brain stem after 9 hrs of guanethidine treatment, whereas those in 4 rats who had been injected only guanethidine were 201.6 223.8 in the former and $570.1 \pm 62.5$ in the latter, showing the levels not significantly but even more augmented than in the 5 rats.

On the other hand, NE in heart was reduced similarly by $\alpha$-methyl-ptyrosine in animals pretreated i.C. with either guanethidine or saline (Fig. 3).

Co-efficients of NE regression illustrated in Fig. 3 were significantly different in brain samples between the 2 groups, while similar in heart (Table II).

\section{Drscussion}

Inhibition of the neurogenic release of endogenous NE and presumably subsequent block of the sympathetic nerve activity by guanethidine ${ }^{11)-13)}$ have been reported to develop in an early stage of administration when tissue levels of NE are not yet significantly eliminated.11),18) The present study was designed with use of this initial effect of guanethidine which is also known to hardly pass through the blood-brain-barrier, ${ }^{11), 18), 19)}$ expecting an influence of the drug on NE metabolism selectively in the brain.

As illustrated in Fig. 2 and Table I, the i.C.-applied guanethidine revealed a dose-relating elevation in blood prcssure for over $9 \mathrm{hrs}$ after injection, during which NE levels in brain portions and heart showed no significant change.

Turnover of endogenous NE in these tissues was estimated on the content regression after inhibition of the rate-limiting step for synthesis by $\alpha$-methyl-ptyrosine, ${ }^{8)-10\}}$ since the effect of guanethidine on the membrane transport mechanism ${ }^{12), 13)}$ might interfere with entry of labelled amines into the brain as already pointed out on the dopaminergic neurones and glial cells. ${ }^{9}$

In the present study, i.C. injected guanethidine blocked the decline of NE content induced by $\alpha$-methyl-p-tyrosine, ${ }^{11), 20)}$ resulting in significantly different coefficients in brain samples but not in heart, to indicate a slowered turnover of $\mathrm{NE}$ selectively in the brain.

Although the suppression of monoamine oxidase and amine uptake by the drug ${ }^{131,19), 20 \text { ) }}$ would also mimic the retardation of $\mathrm{NE}$ metabolism, the present reduction in NE turnover of the brain appears to be derived mainly in block of NE release by the centrally administered guanethidine. ${ }^{11)-13), 18)-20}$ ) 
When considering the depressor response to centrally applied reserpine ${ }^{21)}$ which is known to facilitate turnover and release of the brain $\mathrm{NE},{ }^{91,201}$ the present elevation in blood pressure seems to be elicited by the suppression of NE turnover in the brain perhaps due to block of the releasing mechanism.

The data would also support the blunted NE metabolism in the brain of rats with experimental hypertension ${ }^{(1)-8)}$ being ascribed to be causatively related with their hypertensive mechanisms, although the sustained state of hypertension would not be identical with acute pressor response as seen in the present study.

The results also appear not to be inconsistent with the speculation on the synaptic activity of the brain NE as inhibitory $\alpha$-adrenergic. ${ }^{22), 23 !}$ However, a lot of evidences indicating (1) the diphasic dose-response relations in blood pressure change by the centrally administered $\alpha$-sympathomimetic amines including $\mathrm{NE},{ }^{211}$ (2) conversion of the relation into a simple dose-pressor reactions by preceding block of the central sympathetic activity, ${ }^{41,21), 24\}}$ (3) alteration of the response by depth of anesthesia, ${ }^{22}$ and (4) possible competition between $\alpha$ - and $\beta$-adrenergic drives in the medullary cardiovascular areas $^{4)}$ all suggest the central adrenoreceptor mechanism being far more complicated, as described elsewhere, ${ }^{26)}$ to interprete conclusively on the present data.

\section{ACKNOWLEDGEMENTS}

The authors are greatly acknowledged to Miss Tomiko Kuba for her excellent technical assistance and to GIBA-Geigy $<$ Japan $>$, Ltd for the kind supply of guanethidine.

\section{REFERENCES}

1. Dahlström A, Fuxe K: Evidence for the existence of monoamine neurones in the central nervous system. Acta Physiol Scand 64: (Suppl 247) 1, 1965

2. Korner PL: Integrative neural cardiovascular control. Physiol Rev 51: 312, 1971

3. Ito A, Schanberg SM: Central nervous system mechanisms responsible for blood pressure elevation induced by p-chlorophenylalanine. J Pharmacol Exp Ther 181: 65, 1972

4. Ito A, Schanberg SM: Maintenance of tonic vasomotor activity by alpha and beta adrenergic mechanisms in medullary cardiovascular centers. J Pharmacol Exp Ther 189: 392, 1974

5. Chalmers JP, Reid JL: Participation of central noradrenergic ncurons in arterial baroreccptor reflexes in the rabbit. Circulat Res 31: 789, 1972

6. Yamori X, Lovenberg W, Sjoerdsma A: Norepinephrine metabolism in brain stem of spontaneously hypertensive rats. Science 170: 544,1970

7. Yamori Y, Ooshima A, Nosaka S, Okamoto K: Metabolic basis for central blood pressure regulation in spontaneously hypertensive rats. In; Spontaneous Hypertension, ed by Okamoto K, Springer-Igaku Shoin, Berlin-Heidelberg-New York-Tokyo, p 73, 1972 
8. Nakamura K, Gerold M, Thoenen H: Experimental hypertension of the rat: Reciprocal changes of norepinephrine turnover in heart and brain stem. Naunyn-Schmiederbergs Arch Pharmakol 268: 125, 1971

9. Costa $\mathrm{E}, \mathrm{Neff} \mathrm{NH}$ : Estimation of turnover rates to study the metabolic regulation of the steady-state level of neuronal monoamines. In; Handbook of Neurochemistry, Vol 4, Control mechanisms in the nervous system, ed by Lajtha A, Prenum Press, New York-London, p 45, 1970

10. Bloom FE, Giarman NJ: Physiologic and pharmacologic considerations of biogenic amines in the nervous system. Ann Rev Pharmacol 8: 229, 1968

11. Nickerson $M$ : Drugs inhibiting adrenergic nerves and structures innervated by them. In; The Pharmacological Basis of Therapeutics, 4th Ed, ed by Goodman LS, Gilman A, The MacMillan Co, London-Toronto, p 549, 1971

12. Mitchell JR, Oates JA: Guanethidine and related agents. I. Mechanism of the selective blockade of adrenergic neurons and its antagonism by drugs. J Pharmacol Exp Ther 172: 100,1970

13. Kirpekar SM, Wakade AR, Dixon W, Prat JC: Effect of cocaine, phenoxybenzamine and calcium on the inhibition of norepinephrine output from the cat spleen by guanethidine. $\mathrm{J}$ Pharmacol Exp Ther 165: 166, 1969

14. Schanberg SM, Schildkraut JJ, Kopin IJ: The effect of pentobarbital on the fate of intracisternally administered norepinephrine- ${ }^{3} \mathrm{H}$. J Pharmacol Exp Ther 157: 311, 1967

15. Zeman W, Innes IRM: Craigie's Neuroanatomy of the Rat, Acad Press, New York, 1963

16. Barchas J, Elderlyi E, Angwin P: Simulataneous determination of indole- and catecholamines in tissue using a weak cation-exchange resin. Anal Biochem 50: 1, 1972

17. Snedecor GW: Statistical Methods, 5th Ed, Iowa State University Press, Ames, 1956

18. Cass R, Spriggs TLB: Tissue amine levels and sympathetic blockade after guanethidine and bretylium. Br J Pharmac Chemother 17: 442, 1961

19. Kuntzman R, Costa E, Gessa GL, Brodie BB: Reserpine and guanethidine on peripheral stores of catecholamines. Life Sci $33: 65,1962$

20. Weiner N, Clouthier G, Bjur R, Pfeffer RI: Modification of norepinephrine synthesis in intact tissue by drugs and during short-term adrenergic nerve stimulation. Pharmacol Rev 24: 203,1972

21. Gagnon DJ, Melville KI: A possible dual role of noradrenaline in cardiovascular responses mediated by the central nervous system. Can J Physiol Pharmacol 46: 595, 1968

22. van Zwieten PA: The central action of antihypertensive drugs mediated by central $\alpha$-receptors. J Pharm Pharmac 25: 89, 1973

23. Schmitt H, Schmitt H, Fenard S: Evidence for an $\alpha$-sympathomimetic component in the inhibitory effects of catapresan on vasomotor centers. Europ J Pharmacol 14: 98, 1971

24. Smookler HH, Severs WB, Kinnard WJ, Buckley JP: Centrally mediated cardiovascular effects of angiotension II. J Pharmacol Exp Ther 153: 485, 1966

25. Toda N, Matsuda Y, Shimamoto K: Cardiovascular effects of sympathomimetic amines injected into the cerebral ventricles of rabbits. Int $\mathrm{J}$ Neuropharmacol 8: 451, 1969

26. Ito A: Possible role of norepinephrine and serotonin in the tonic vasoregulatory function of the brain stem in the rat. Aut Nerv Syst 11: 70, 1974 (in Japanese). 